\title{
Neisseria gonorrhoeae: un patógeno díscolo. Conceptos microbiológicos, resistencia a antimicrobianos y su vigilancia epidemiológica en Chile
}

\section{Neisseria gonorrhoeae: a wayward pathogen. Microbiological concepts, antimicrobial resistance and its epidemiological surveillance in Chile}

Mirko Ortiz Á. ${ }^{1}$, Edgardo Santander P. ${ }^{1}$ y Judith Lugo P. ${ }^{2}$

${ }^{1}$ Universidad Arturo Prat-Chile.

Universidad de Zulia-República Bolivariana de Venezuela.

Sin financiamiento.

Sin conflictos de interés.

Recibido: 11 de noviembre de 2020 / Aceptado: 9 de junio de 2021

\section{Resumen}

Neisseria gonorrhoeae es un diplococo gramnegativo, no móvil, esporulado, aerobio o anaerobio facultativo, catalasa y oxidasa positivas. Las infecciones de transmisión sexual causadas por este microorganismo son un problema de salud pública definido como tal desde el siglo XIX, representando una gran amenaza para la salud humana debido a la su alta prevalencia y multirresistencia a antimicrobianos. En las últimas décadas han aumentado los reportes de cepas resistentes a penicilina, fluoroquinolonas, sulfonamidas, tetraciclina, macrólidos, y más recientemente a cefalosporinas y azitromicina. Tal panorama ha generado preocupación a nivel mundial, debido al aumento de casos de gonorrea asociados a cepas multirresistentes. En Chile se desarrolló desde el 2010 hasta el 2018 el Programa de Vigilancia de $N$. gonorrhoeae a nivel nacional con el objeto de caracterizar esta infección en las regiones y registrar la resistencia a los antimicrobianos. Esta revisión presenta un análisis sistemático bibliográfico, actualizado, de los principales aspectos de este microorganismo, su respuesta a antimicrobianos, y entrega pautas de diagnóstico y tratamiento, a la espera de avanzar en la comprensión del mecanismo molecular y las interacciones metabólicas e inmunológicas que determinan la infección, con miras a diseñar una vacuna efectiva.

Palabras clave: Neisseria gonorrhoeae; gonococo; enfermedad de transmisión sexual; resistencia antimicrobiana; revisión.

\section{Abstract}

Neisseria gonorrhoeae is a nonmotile, sporulated, aerobic or facultative anaerobic gram-negative diplococcus, catalase and oxidase positive. Sexually transmitted infections caused by this microorganism were established as public health problem since the 19th century, representing a great threat to human health due to its high prevalence and multi-resistance to antimicrobials. In recent decades, reports of strains resistant to penicillin, fluoroquinolones, sulfonamides, tetracycline, macrolides, and more recently to cephalosporins and azithromycin have increased. Such a panorama has generated concern worldwide, due to the increase in cases of gonorrhea associated with multi-resistant strains. In Chile, from 2010 to 2018, the National Surveillance Program for $N$. gonorrhoeae was developed in order to characterize this infection in the regions and record antimicrobial resistance. This review presents an updated, systematic bibliographic analysis of the main aspects of this microorganism, its response to antimicrobials, and provides diagnostic and treatment guidelines, while waiting to advance in the understanding of the molecular mechanism and the metabolic and immunological interactions that determine infection, with a view to designing an effective vaccine.

Keywords: Neisseria gonorrhoeae; gonococcus; sexually transmitted diseases; antibiotic resistance; review.

\section{Correspondencia a:}

Judith Lugo P.

judlugop@gmail.com 


\section{Introducción}

$N$

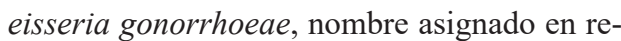
conocimiento a Neisser Albert, quien la describió, y gonorrhoeae: gonos $=$ semillas y rhoe $=$ fluir, términos griegos introducidos por Galeno, es la etiología de la enfermedad comúnmente llamada "gonorrea" o "blenorragia", "purgaciones" o "gota militar". Este microorganismo bacteriano representa un problema de salud pública, mencionado como tal desde el siglo XIX, y en la actualidad, una enfermedad de transmisión sexual relevante, por ser frecuente y representar una gran amenaza para la salud humana debido a su emergente multirresistencia a antimicrobianos ${ }^{1}$.

Como cualquier bacteria, $N$. gonorrhoeae se reproduce asexualmente por división binaria, originándose dos células hijas aproximadamente del mismo tamaño a partir de una célula madre. Esta división no es completa ya que no se separan los tabiques o septos de cada una de las células que se originan, y de allí que se dispongan en pares ${ }^{2}$. Este diplococo intracelular gramnegativo -en el lenguaje diario se le denomina "gonococo"- es una bacteria inmóvil, asporulada, dependiente de oxígeno, catalasa y oxidasa positivas. Se le define como un patógeno "por excelencia" pues siempre está asociado a la mencionada enfermedad venérea $^{3}$ cuya contagiosidad es muy elevada.

En el hombre esta enfermedad se manifiesta comúnmente como uretritis aguda, y en la mujer causa complicaciones como salpingitis aguda que frecuentemente provoca infertilidad ${ }^{4}$.

El diagnóstico más usado para $N$. gonorrhoeae es el cultivo bacteriano, aunque también se recomienda hacer un frotis del fluido y tinción de Gram. La identificación de especie se alcanza con las pruebas bioquímicas; otros métodos de diagnóstico confirmatorios se basan en ensayos moleculares a través de pruebas de amplificación de ácidos nucleicos ${ }^{5}$.

En las últimas décadas han aumentado los reportes de cepas de $N$. gonorrhoeae resistentes a penicilina, fluoroquinolonas, sulfonamidas, tetraciclina, macrólidos, y más recientemente, a cefalosporinas y azitromicina, por sí solas o combinadas ${ }^{5}$. Tal panorama ha generado preocupación a nivel mundial, debido al aumento de casos de gonorrea asociados a cepas multirresistentes.

En Chile, el Laboratorio de Agentes de Infecciones de Transmisión Sexual de la Sección Bacteriología del Instituto de Salud Pública (ISP) condujo, desde el 2010 hasta el 2018, una vigilancia de la resistencia antimicrobiana a las cepas de $N$. gonorrhoeae enviadas por los laboratorios públicos y privados de la red asistencial del país. Este programa realiza actualmente dicha vigilancia epidemiológica, de acuerdo con lo indicado en el Decreto Supremo No $7 / 2019$, artículo 5º Notificación de Enfermedades Transmisibles de Declaración Obligatoria.
A través de esta estrategia se logró detectar 12.457 cepas de $N$. gonorrhoeae a nivel nacional y demostrar la total susceptibilidad in vitro a ceftriaxona y cefixima en las cepas confirmadas; sin embargo, azitromicina mostró una disminución en su actividad in vitro. Asimismo, la sensibilidad a tetraciclina se redujo. Por otro lado, se pudo comprobar un aumento de la resistencia antimicrobiana a penicilina $\mathrm{G}$ y a ciprofloxacina en los ocho años de análisis. Ante lo cual, resulta muy importante evaluar en forma permanente la sensibilidad de las cepas aisladas, luego de llevar a cabo un diagnóstico acertado. Así, se pretende evitar la diseminación de la bacteria, especialmente en los casos asintomáticos, prescribir un buen tratamiento e implementar campañas de salud en la población, mientras se avance en comprender el mecanismo molecular y las interacciones metabólicas e inmunológicas que determinan una infección, con miras a diseñar una vacuna efectiva.

\section{Generalidades de Neisseria gonorrhoeae}

La gonorrea fue reconocida en el siglo II a.C. por Galeno. También se encontraron referencia de esta infección en antiguos testamentos y en historias escritas por varias culturas. Sin embargo, Albert Neisser logró identificar la bacteria y diferenciar esta enfermedad de la sífilis en 1879, a mediados del siglo XIX7. Desde ese momento a la actualidad, la taxonomía de $N$. gonorrhoeae ha sido un gran debate científico, sufriendo varias reorganizaciones en el tiempo desde que Stackebrandt y cols. (1988), a través de la hibridación de [ARNr]ARN ADN-ribosómico, de ADN-ADN y la secuenciación de 16S ARNr, lograron ubicarla en la clase $\beta$-proteobacteria y asignarle un orden y familia propia diferenciándolas de $\gamma$-proteobacterias donde prevalece otros órdenes y familias como Pseudomonas y Moraxella (Tabla 1).

Neisseria gonorrhoeae es un diplococo Gram negativo -la tinción de Gram directo del fluido purulento permite visualizar diplococos intracelulares dispuestos en "granos de cafe" - de lento crecimiento y difícil de cultivar. El medio de cultivo agar chocolate o GC adicionado, es el medio enriquecido más útil para el cultivo de esta bacteria, mientras que el medio de cultivo Thayer-Martin es el medio selectivo de elección para el aislamiento de la bacteria cuando se trabajan muestras clínicas con microbiota acompañante ${ }^{7}$. El medio de Thayer Martin contiene vancomicina, nistatina, colistina y trimetoprim que inhibe el crecimiento de la microbiota normal (especies grampositivas, gramnegativas y hongos), pero permite el crecimiento de $N$. gonorrhoeae ${ }^{3}$. El tamaño celular oscila entre 0,6 y $1 \mu \mathrm{m}$, siendo su promedio de $0,8 \mu \mathrm{m}$ de diámetro; bajo el microscopio de luz se visualizan dentro de los neutrófilos polimorfonucleares ${ }^{8}$. Generalmente crecen a temperatura de $35^{\circ} \mathrm{C}$ a $37^{\circ} \mathrm{C}$ en una atmosfera de $\mathrm{CO}_{2}$ al 5\% (Figura 1). 
También es reconocido por ser un microorganismo fastidioso, tener un cromosoma circular cuyo genoma tiene una longitud de 2,14 Mbp con un contenido de GC $52,4 \%$ y 2.179 proteínas. Esta bacteria es catalasa y oxidasa positiva, sensible a ácidos grasos. La bacteria no crece en ausencia del aminoácido cisteína, pudiendo obtener energía del piruvato y lactato. Estos microorganismos aerobios, capnofilios, son inmóviles, no tienen cápsula, no forman esporas, no son acidorresistente.

\section{Habitat}

El ser humano es el único hospedero natural de esta bacteria, siendo la edad más frecuente de cultivarla entre los 15 a 24 años. Los portadores pueden ser tanto sintomáticos como asintomáticos; en especial, las mujeres no presentan síntomas y la transmisión es por coito heterosexual u homosexual ${ }^{9}$.

Crece en la superficie húmeda de las mucosas incluyendo el cérvix, útero, y trompas de Falopio en las

\begin{tabular}{llll|}
\hline \multicolumn{2}{l}{ Tabla 1. Taxonomía de Neisseria gonorrhoeae } \\
\hline Reino & Bacteria & \\
Filo & Proteobacteria & \\
Clase & $\gamma$-Proteobacterias & & \\
Orden & Pseudomonadales & & Neisseriales \\
Familia & Pseudomonadaceae & Moraxellaceae & Neisseriaceae \\
Género & Pseudomonas & Moraxella & Neisseria \\
Especie & P. aeruginosa & M. lacunata & N.gonorrhoeae \\
\hline
\end{tabular}

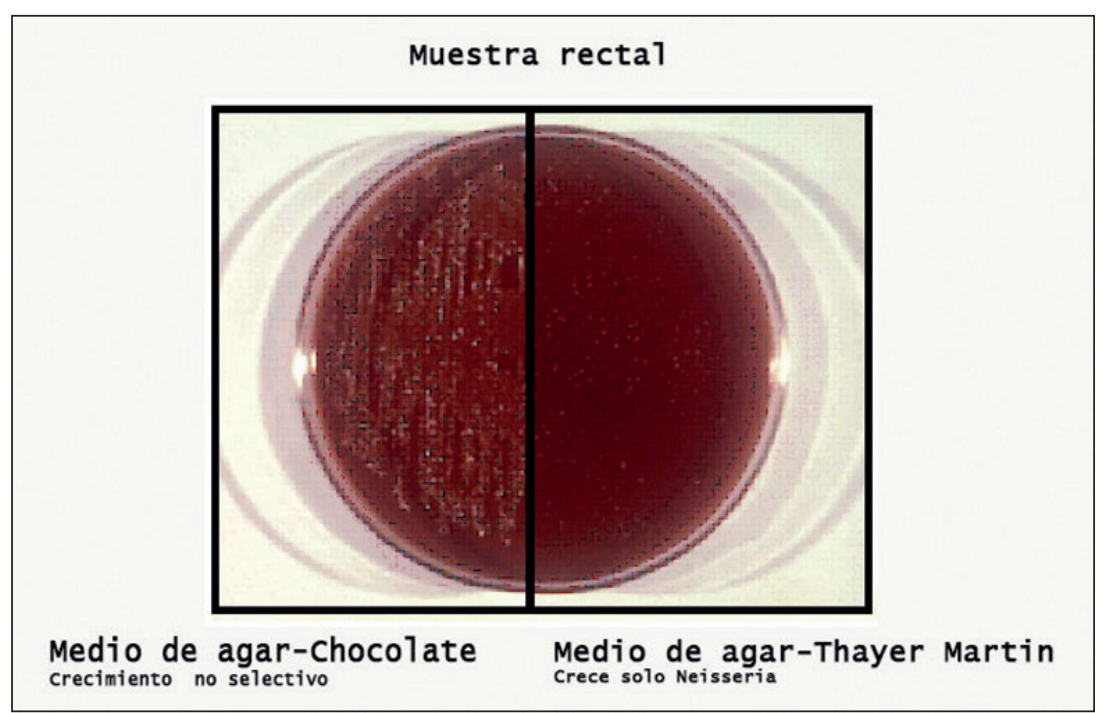

Figura 1. Colonias de Neisseria gonorrhoeae tomada de una muestra rectal que crece en agarChocolate no selectivo y en agar- Thayer Martin que solo selecciona N. gonorrhoeae y N. meningitidis. Fuentes: Modificado de Principios de Microbiología Médica III Edición, 2017. mujeres, así como en la uretra masculina ${ }^{11}$. Sin embargo, también puede encontrarse en la boca, faringe, ano ${ }^{12}$ y su aparición es menos frecuente en articulaciones, causando artritis gonocócica, (artritis séptica) que generalmente se detecta en pacientes inmunodeprimidos o con infección por $\mathrm{VIH} / \mathrm{SIDA}^{13}$. Las mujeres que tengan gonorrea sin tratar pueden transmitirle estas bacterias al bebé durante el parto causando la conjuntivitis gonocócica (oftalmía neonatal) ${ }^{14}$.

\section{Patogénesis y factores de virulencia en Neisseria gonorrhoeae}

Neisseria gonorrhoeae presenta el fenómeno biológico conocido como variación de fase, el cual consiste en que las cepas carentes de pilis (no patógenas) pueden expresarlos o incluso modificarlos, variando su composición antigénica, lo que le permite evadir, en parte, la respuesta inmune del hospedero ${ }^{15}$.

El gonococo puede infectar a células ciliadas y no ciliadas. Se ha demostrado que la infección gonocócica ocurre en dos fases. Primero la adhesión a la mucosa y luego la invasión de la célula epitelial. En la etapa inicial de la adhesión sucede la primera interacción interviniendo factores como: carga negativa de superficies (bacteria y célula hospedera), $\mathrm{pH}$ e interacciones hidrofóbicas, siendo las más importantes la adhesión del microbio invasor a un receptor sobre la célula hospedera. Los pili, junto a las proteínas Opa, permiten la adhesión a los receptores (CD46, CD66, integrinas) que se encuentran en la superficie epitelial ${ }^{16}$. Existen también, receptores específicos únicos en su tipo, como los ubicados en enterocitos o células uroepiteliales humanas; uno de estos receptores es el GD, gangliósido que interactúa con las adhesinas (fimbrias o pilis) ${ }^{3}$. La invasión al hospedero comienza atravesando la célula epitelial, al interior de vacuolas, para acceder a la matrix subepitelial. La bacteria tiene un sistema de secreción que inyecta múltiples proteínas al interior de la célula hospedera. Algunas de éstas ocasionan un reacomodo en el citoesquelético y reacciones en cadena, que permite engullir a la bacteria. Dentro del citosol, las bacterias lisan la membrana vacuolar, escapan y se diseminan. Una proteína de la superficie de la bacteria se une a la superficie celular del hospedero e induce su propia endocitosis. Dentro de la célula, algunas escapan, mientras que otras se multiplican en el fagosoma donde el gonococo usualmente se localiza, causando una intensa reacción inflamatoria ${ }^{17}$.

Características interesantes de esta bacteria son las numerosas estructuras superficiales (Pili, Opa, LOS), que desempeñan una función esencial en el proceso infeccioso. Sin embargo, la bacteria en su totalidad es importante por su virulencia y efectos biológicos (Tabla 2, Figura 2). 


\section{Diagnóstico}

Existe una variedad de bacterias que se transmiten por contacto sexual. No todas las infecciones de transmisión sexual tienen cura; la gonorrea sí es curable. Esta infección bacteriana tiene un período de incubación de 2 a 5 días (extremos 1-7) ${ }^{4}$. Cuando el ser humano presenta síntomas, la identificación de la gonorrea se logra mediante la obtención de la muestra en hisopos (rayón o dacrón) estériles, a partir de sitios expuestos durante el contacto sexual como el tracto genital, uretra, recto y orofaringe en el hombre, mientras que en la mujer la muestra se obtiene de las glándulas de Bartolino, trompas de Falopio, endometrio, sangre, liquido articular y lesiones de la piel; también se puede realizar una muestra no invasiva como la orina ${ }^{5}$ en ambos sexos.

$\mathrm{Su}$ transporte debe ser en hisopos húmedos; para su recuperación, la temperatura debe estar entre $35^{\circ}$ a $37^{\circ} \mathrm{C}$, la atmosfera debe contener $\mathrm{CO}_{2}$ y humedad, el medio de cultivo debe ser suplementado (agar chocolate o GC), el tiempo de cultivo normalmente es de $48 \mathrm{~h}$, pero se recomienda subcultivo cada 18 a $24 \mathrm{~h}$ para mayor viabilidad. El almacenamiento de una cepa puede ser congelándola en un medio de tripticasa soya con glicerol $15 \%$ que se suspende en nitrógeno líquido, o puede mantenerse en un congelador a $-70^{\circ} \mathrm{C}$ porque las cepas sobreviven un tiempo corto a menor temperatura ${ }^{18}$.

Para realizar un correcto diagnóstico de esta cepa, ya recuperada en un medio de cultivo no selectivo, se procede a efectuar un subcultivo en medio selectivo, para obtener un cultivo puro, y colonias individuales. Una orientación diagnóstica rápida se logra al realizar una tinción Gram, o una tinción simple con azul de metileno ${ }^{19}$; para confirmar el diagnóstico se efectúan pruebas bioquímicas como la reacción oxidasa, reacción de superoxol 4+/catalasa, resistencia a colistina, prueba de reducción a nitrato, prueba de producción de polisacárido, prueba de producción de ácido y prueba enzima-sustrato. Sin embargo, en la actualidad se ocupa un método de análisis genómico que resulta ser más certero, llamado prueba de amplificación de ácidos nucleico (NAAT) ${ }^{20}$.

- Tinción de Gram o azul de metileno: Este método generalmente se utiliza para describir la morfología de los diplococos encontrados al interior del macrófago los que pueden adoptar la morfología de células en granos de café.

- Prueba de oxidasa: En este método se utiliza el reactivo de Kovac (solución 1\% de N, N', N'-tetrametil- p- dihidroclorofenilendiamina) para detectar la presencia de citocromo $\mathrm{C}$ en la cadena respiratoria del microorganismo bacteriano y el resultado será positivo si se visualiza el color violeta.

- Superoxol/catalasa: El peróxido de hidrogeno $\left(\mathrm{H}_{2} \mathrm{O}_{2}\right)$ es el reactivo clave; se diferencian ambos métodos por
Tabla 2. Factores de virulencia en Neisseria gonorrhoeae

Factor de virulencia Efecto biológico

Fimbrias (pili)

Proteína que interviene en la adhesión inicial a las células humanas (ej., epitelio vaginal, trompa de Falopio y cavidad oral) e interfiere en la muerte producida por los neutrófilos.

Porina PorA/PorB Proteína que facilita la supervivencia intracelular al evitar la fusión de las fagolisosomas en los neutrófilos.

Proteína Opa Proteína de opacidad que interviene en la adhesión firme a las células eucariotas.

Proteína RmP Proteína de reducción modificable que protege a otros antígenos de superficie (proteína Por, LOS) de los anticuerpos bactericidas.

Proteína H.8 Epítopos que reaccionan con el anticuerpo monoclonal H.8."

Proteasa IgAl Destruye la inmunoglobulina Al.

Fj-lactamasa Hidroliza el anillo |3-lactámico de la penicilina.

Proteína Fbp Proteína de unión al hierro, se expresa cuando el suministro disponible de hierro es limitado.

LOS

Componente endotóxico de las células bacteriana, Interviene en la adhesión bacteria-bacteria. (formación de microcolonias); provoca la respuesta inflamatoria y desencadena la liberación de FNT- $\alpha$.

Plásmido

Confieren resistencia a antimicrobianos, genes estructurales TEM-1 para las $\beta$-lactamasas

el porcentaje de $\mathrm{H}_{2} \mathrm{O}_{2}$, superoxol utiliza $\mathrm{H}_{2} \mathrm{O}_{2}$ al $30 \%$ y catalasa al 3\%. En ambos, $N$. gonorrhoeae reacciona de forma explosiva (producción de burbujas), en comparación a la mayoría de las otras especies de Neisseria.

- Resistencia a colistina: Se usa un disco impregnado con $10 \mu \mathrm{g}$ de colistina, en un medio de cultivo selectivo y se determina su sensibilidad al antimicrobiano a través de la medición del halo de inhibición alrededor del disco. Las cepas de $N$. gonorrhoeae son resistentes a colistina y crecerán sin problemas.

- Prueba de reducción de nitrato: Se usa para reducir el nitrato $\left(\mathrm{NO}_{3}\right)$ a nitritos $\left(\mathrm{NO}_{2}\right)$ o nitrógeno gaseoso. Se utilizan tres reactivos: nitrato (A), $\alpha$-naftilamina (B) y polvo de zinc. Si las bacterias son capaces de reducir el nitrato a nitrito son positivas por el cambio de color del medio debido a la producción de nitrito; por reacciones entre el reactivo A y $\mathrm{B}$, más la reducción de nitrato a nitrito por la bacteria, se forma un color rojo, lo cual es una respuesta positiva en esta prueba. Para comprobar si las cepas son negativas, se debe agregar polvo de zinc después de la incubación de A y B; si cambia de color a rojo son negativas (el nitrato es reducido por el polvo de zinc). 
Figura 2. Esquema de la estructura patogénica de $N$. gonorrhoeae macro y microscópica. Fuente: Propia.

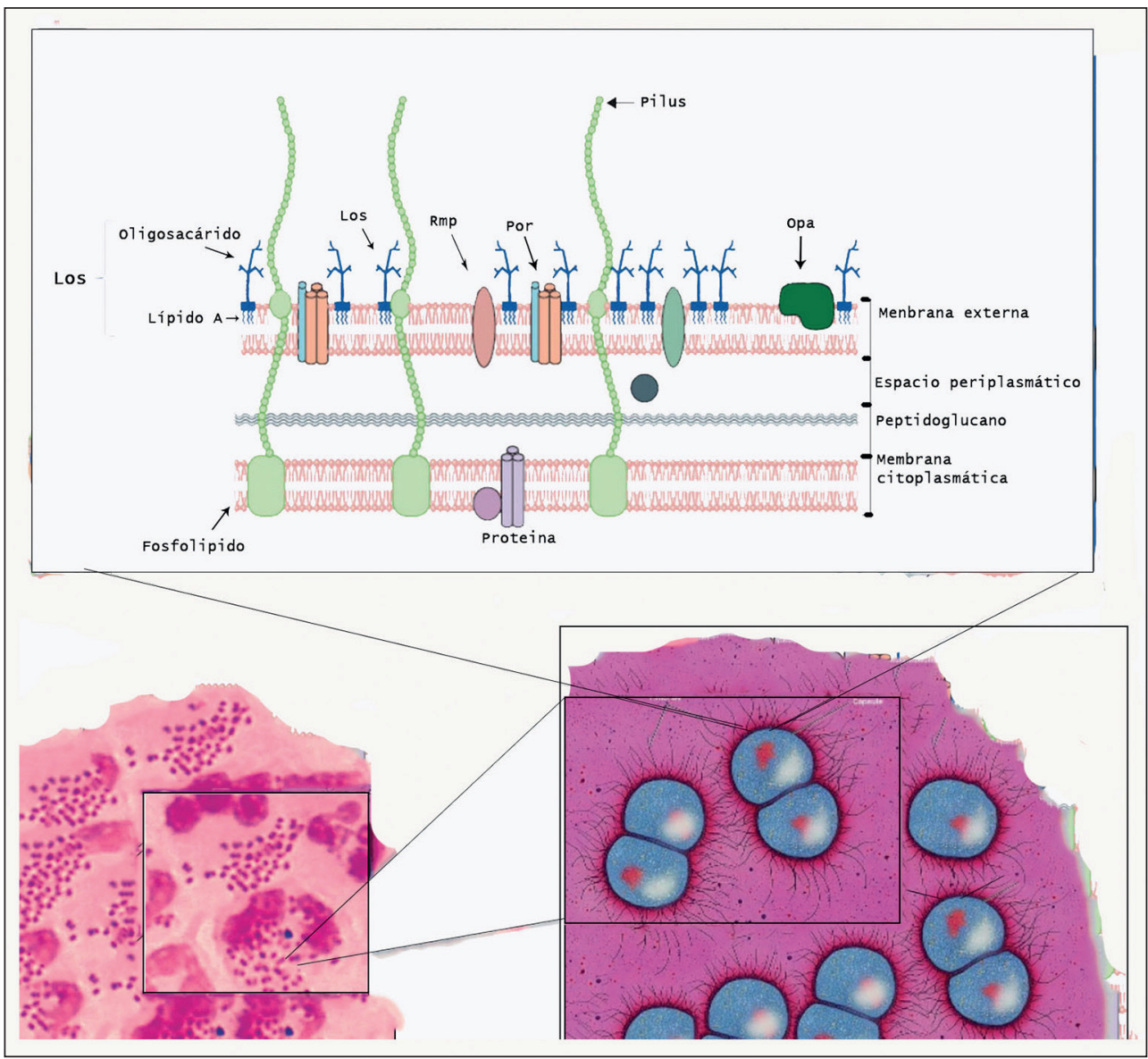

- Prueba de producción de polisacárido: Cuando el microorganismo crece en medio suplementado con sacarosa, se produce un polisacárido, parecido al almidón Al adicionar una gota de yodo de Gram al cultivo, el medio se tiñe de color azul purpura oscuro a café o negro. Si el cultivo no cambia de color se considera negativo siendo el caso de $N$. gonorrhoeae. No es posible detectar polisacáridos en un medio que contiene sacarosa, por lo que se recomienda utilizar el medio base de triptona-soya.

- Prueba de producción de ácido: Esta prueba detecta la producción de ácido a partir de glucosa, maltosa, lactosa y sacarosa. Neisseria gonorrhoeae sólo produce ácido a partir de la glucosa; se recomienda comparar los resultados con otras cepas ( $N$. meningitidis, $N$. lactamica y $M$. catarrhalis, $N$. cinerea), porque suelen presentarse falsos positivos.

- Prueba enzima-substrato: Esta prueba cromogénica detecta enzimas (ß-galactosidasa, $\gamma$-glutamilaminopeptidasa e hidroxiprolil-aminopeptidasa), cambiando de color si están presentes o no; $N$. gonorrhoeae sólo produce hidroxiprolil-aminopeptida- sa. La combinación de estas pruebas permite identificar de manera efectiva a $N$. gonorrhoeae como se muestra en la Figura 3.

- Prueba de amplificación de ácidos nucleicos: La prueba de ácido nucleico o NAAT es un término genérico que se refiere a todas las pruebas moleculares usadas para detectar y amplificar material genómico (ARN o ADN), característico de $N$. gonorrhoeae y permite descartar a otros microorganismos.

\section{Mecanismos de resistencia a antimicrobianos}

La resistencia a los antimicrobianos se debe, en gran parte, a la modificación de la estructura celular, la permeabilidad del antimicrobiano en el patógeno o a procesos de intercambiando de información genética. Todos estos procesos han optimizado los mecanismos moleculares para evitar el biocida terapéutico ${ }^{21}$, y así persistir en la población humana. Estos mecanismos moleculares de resistencia a los antimicrobiano pueden suceder de las siguientes formas: 


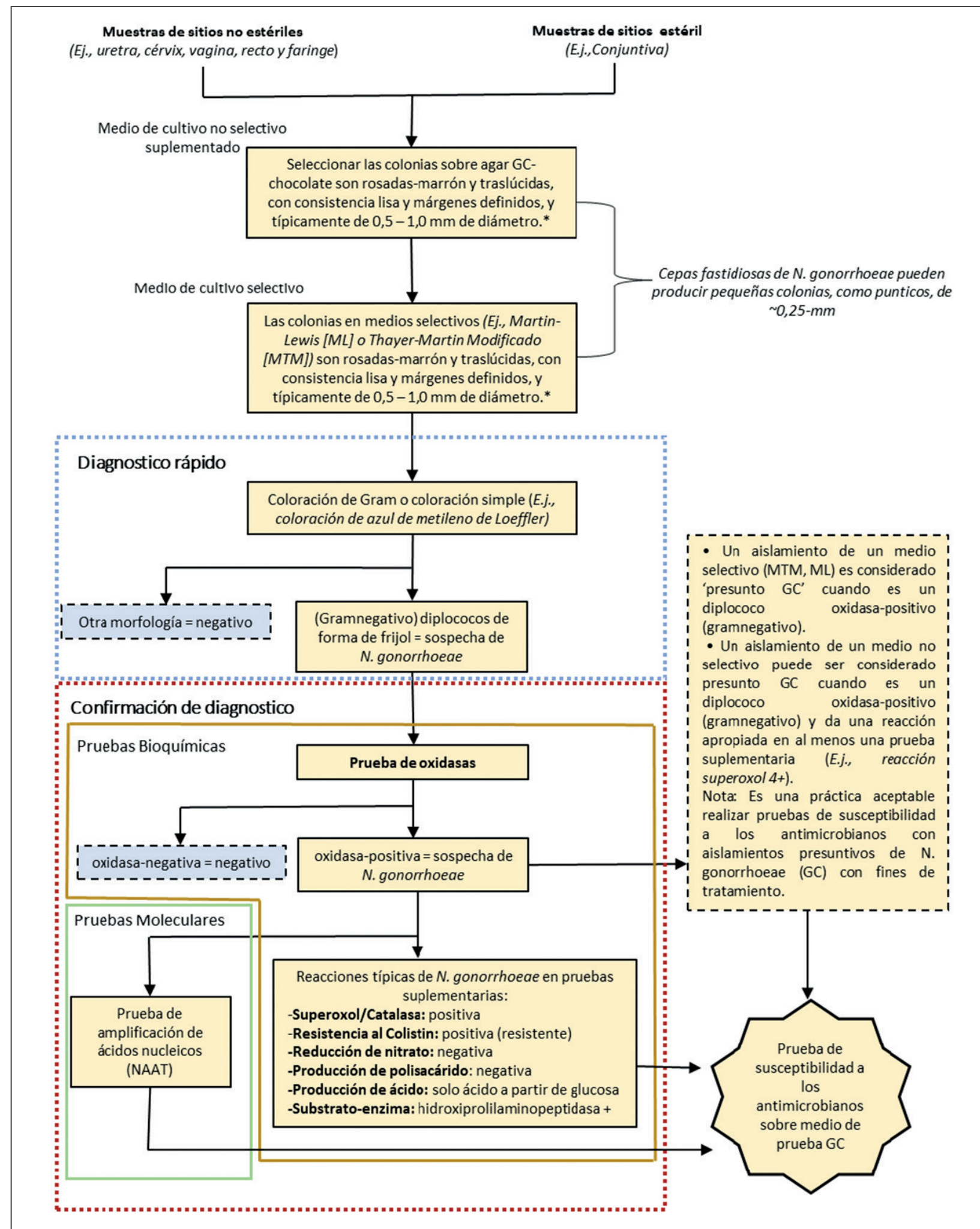

Figura 3. Diagrama de flujo de diagnóstico rápido y confirmación diagnóstico de gonorrea (ITS). Identificación de N. gonorrhoeae, a través de técnicas bioquímicas y moleculares. Fuente: Modificado del Manual de Laboratorio para la Identificación y Prueba de Susceptibilidad a los Antimicrobianos de Patógenos Bacterianos de Importancia para la Salud Pública en el Mundo en Desarrollo. OMS, 2004. 


\section{—}

Artículo de Investigación

- Mutación del receptor: Si el (receptor) sitio blanco cambia tras una mutación, impide la vinculación del fármaco.

- Modificación del antimicrobiano: Las cepas resistentes producen una enzima que modifica la molécula del fármaco.

- Impermeabilidad de la bacteria: La bacteria cierra sus poros. El antimicrobiano no puede penetrar.

- Expulsión del antimicrobiano: Algunas bacterias son capaces de rechazar los antimicrobianos por expulsión fuera de la célula.

Neisseria gonorrhoeae es un microorganismo resistente y genéticamente diverso, capaz de captar ADN en todas las etapas de su ciclo de vida desde otras cepas de gonococo, así como de bacterias de otros géneros. Esta bacteria puede hacerse resistente a los agentes antimicrobianos por mecanismos que incluyen la destrucción del fármaco mediante enzimas; modificación o protección del receptor; salida de agentes antimicrobianos y disminución de la afluencia de agentes antimicrobianos. La resistencia

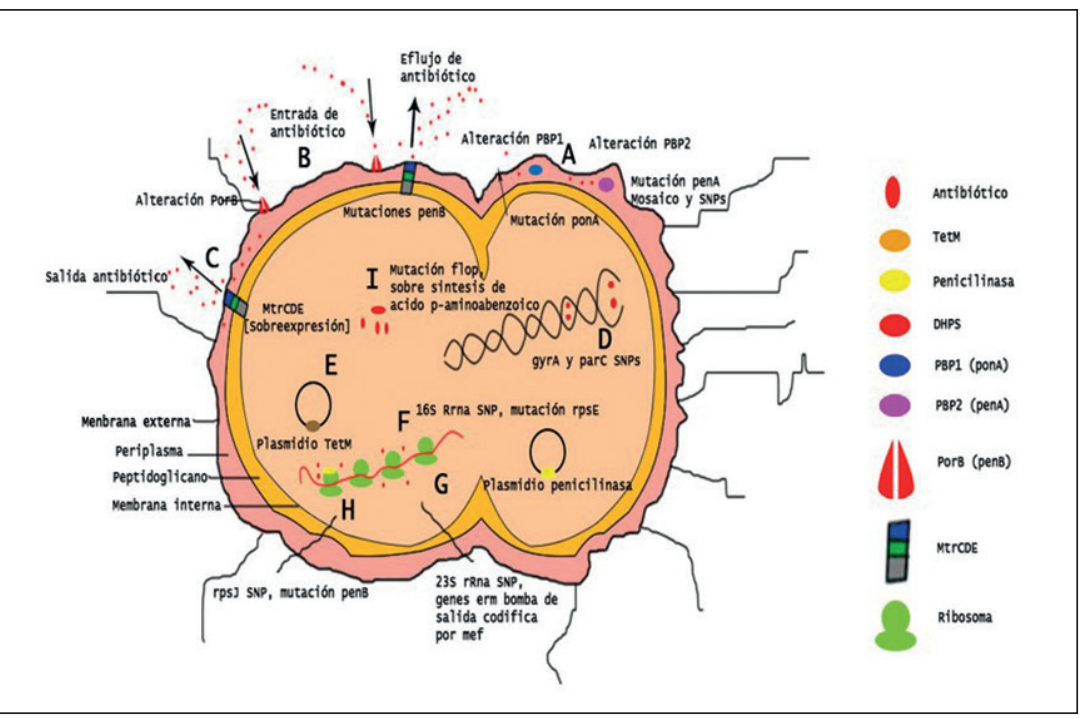

Figura 4. Mecanismos de resistencia a antimicrobianos en aislados de $N$. gonorrhoeae A. $\beta$-LACTÁMICOS, CEFALOSPORINA; Mutaciones en proteínas de unión a penicilina (PBP1 y PBP2). B. $\beta$-LACTÁMICOS, CEFALOSPORINA, TETRACICLINAS; Mutaciones en penB, que codifican una proteína importante de la membrana externa. C. $\beta$-LACTÁMICOS, CEFALOSPORINA, TETRACICLINAS, MACROLIDOS; Las mutaciones en mtrR, que codifica la proteína represora MtrR provocan una sobreexpresión que aumenta la salida de antimicrobianos. D. FLUOROQUINOLONAS Mutaciones en la ADN girasa (gyrA) y la topoisomerasa ( $p a r C$ ) que reducen la unión a estas enzimas. E. $\beta$-LACTÁMICOS; Penicilinasa codificada por plásmido que hidroliza el anillo $\beta$-lactámico. F. ESPECTINOMICINA; Una mutación de SNP y rPSE de ARNr $16 \mathrm{~S}$ inhibe la unión a la diana ribosómica. G. metilasas de ARNr en 23S. El ARNr compromete la unión. La sobreexpresión de la bomba de salida MtrCDE y/o las bombas de salida codificadas por mef y macAB aumentan la salida del antimicrobiano. H. TETRACICLINAS; Un SNP en rpSJ que codifica la proteína ribosómica y la proteína TetM inhibe la unión a la diana ribosómica. I. SULFANAMIDAS; Mutaciones en folP que codifica DHPS y la sobre síntesis del ácido p-aminobenzoico confieren resistencia. Fuente: Modificado de Antibiotic resistance in Neisseria gonorrhoeae: will infections be untreatable in the future? Dillon J-A, Parti R, Thakur S. 2015. puede surgir a través de mutaciones espontáneas en diferentes genes cromosómicos, la absorción de ADN mutado mediante transformación o mediante mecanismos conjugativos mediados por plásmidos ${ }^{22}$. Una variedad de mecanismos de resistencia, suele estar presente en una sola célula gonocócica (Figura 4) y una combinación de genes, junto con mutaciones dentro un gen específico ${ }^{23}$.

\section{Sulfamidas}

Estos antimicrobianos funcionan compitiendo con ácido p-aminobenzoico (PABA) para la formación de la enzima dihidropteroato sintasa (DHPS), Son análogos para la síntesis del ácido paraaminobenzoico, que previene la formación de tetrahidrofolato necesario para la síntesis de ADN. Mutaciones en folP, que codifica DHPS, reduce la afinidad de DHPS por las sulfonamidas ${ }^{23,24}$. Los gonococos también pueden hiperproducir PABA superando la inhibición efecto de las sulfonamidas.

Hoy en día la resistencia de $N$. gonorrhoeae hacia este fármaco está muy avanzada y su uso terapéutico es poco habitual.

\section{$\beta$-lactámicos}

Son fármacos bactericidas que actúan inhibiendo la síntesis de la pared celular bacteriana. Inhiben la transpeptidación en las etapas finales de la síntesis del peptidoglicano, polímero esencial para la pared bacteriana. La alteración de la pared produce la activación de enzimas autolíticas que provocan la destrucción de la bacteria por su modo de acción. Las penicilinas, cefalosporinas, monobactámicos y carbapenemes están implicados en la resistencia antimicrobiana. Estos fármacos ocupan las proteínas de unión (PBP) de $N$. gonorrhoeae, PBP1 (ponA) y PBP2 (penA) que catalizan los enlaces cruzados de péptidos entre hebras de glucanos adyacentes de peptidoglicano, siendo PBP2 el objetivo principal en $N$. gonorrhoeae. Diferentes mutaciones puntuales en PBP2 reducen su tasa de acilación por $\beta$-lactámicos, lo que resulta en una menor susceptibilidad. Los aislados con mutaciones en penA se caracterizan por la inserción de residuos y también puede portan varias mutaciones adicionales en la región carboxilo terminal de la proteína ${ }^{24,25}$.

\section{Aminoglucósidos}

Son compuestos policatiónicos que contienen un aminociclitol con aminoazúcares cíclicos ligados por enlaces glicosídicos. Se unen a los ribosomas bacterianos (fracción 30S), ocasionando la producción de proteínas defectuosas, o bien, la inhibición total de la síntesis proteica de la bacteria. Se ha registrado resistencia hacia espectinomicina y kanamicina, causada por mutaciones en el ARNr $16 \mathrm{~S}$ y en la proteína ribosomal $30 \mathrm{~S} \mathrm{~S} 5^{26}$. Una mutación en la proteína S5 puede conferir una resistencia de bajo nivel. Se ha descrito resistencia a aminoglucósidos 
en bacterias, incluyendo disminución de la absorción y acumulación de fármacos, modificación de la diana ribosómica, la salida del fármaco y la modificación enzimática del fármaco ${ }^{27}$.

\section{Tetraciclinas}

$\mathrm{Su}$ estructura química comparte el mismo núcleo tetracíclico, las glicilciclinas (tigeciclina) que derivan de la minociclina por sustitución de un resto de glicina, y normalmente se recetan a pacientes alérgicos a penicilina. A diferencia de las penicilinas y aminoglucósidos, son en su mayoría bacteriostáticos a concentraciones que alcanzan en los tejidos humanos, pero actúan de forma similar a aminoglucósidos interfiriendo la síntesis proteica de los microorganismos susceptibles. Los niveles de resistencia a tetraciclina pueden desarrollarse debido a varias mutaciones en $m t r R$, así como por la sustitución de carga aminoácidos en PorB. Una mutación en la proteína ribosomal 30S S10 ( rps J), involucrada en la unión de ARNt a ribosomas, modula la afinidad de tetraciclina por su sitio de unión de ARNr. Junto con mutaciones en $m$ trR $y$ por $B$, esta mutación causa una resistencia cromosómica de alto nivel a tetraciclina ${ }^{29,30}$.

\section{Quinolonas}

$\mathrm{Su}$ estructura química básica común es 4-oxo-1,4dihidroxiquinoleina, compuesta por dos anillos, uno de tipo piridona y otro aromático, que puede ser bencénico. La incorporación de un átomo de flúor origina las fluorquinolonas. La acción de las quinolonas interfiere con el metabolismo del ADN bacteriano por inhibición de dos enzimas, ADN girasa y topoisomerasa IV. Estas enzimas catalizan el superenrollamiento de la molecula de ADN; la ADN girasa se compone de subunidades GyrA y GyrB, codificadas por gyrA y gyrB, respectivamente. La función de la topoisomerasa IV, codificada por $\operatorname{par} \mathrm{C}$, no se comprende bien. Existen mutaciones características puntuales dentro de la resistencia a las quinolonas en las regiones determinantes de los genes gyrA y parC que están asociadas con resistencia. En el gonococo se observan mutaciones en gyrA o con mutaciones tanto en gyr $A$ como en $\operatorname{par} C^{31-33}$.

\section{Macrólidos/azálidas}

Este grupo de antimicrobianos: eritromicina / azitromicina, entre otros, actúan uniéndose a la subunidad ribosómica 50S y logran inhibir el alargamiento de las cadenas peptídicas, Están compuestos por un anillo lactónico macrocíclico que puede tener 14, 15 o 16 átomos de carbono, al que se unen diversos desoxiazúcares, que provocan un efecto bacteriostático o bactericida. La salida del fármaco y/o modificación de la diana ribosomal están relacionada con la resistencia bacteriana a estos fármacos, ya sea por modificación del ARNr 23S o mutaciones genéticas en $23 \mathrm{~S}$ $\mathrm{ARNr}^{34}$. El flujo de salida de MtrC-MtrD-MtrE, regulado por el represor MtrR en el sistema de $N$. gonorrhoeae exporta macrólidos. El aumento de la salida puede ocurren por deleción o inactivación insercional del gen $m t r R$ o el promotor $m t r R$. Otro eflujo de macrólidos es la bomba codificada por mef y se ha detectado en casos particulares, aunque su contribución a la resistencia a macrólidos gonocócicos sigue sin estar clara ${ }^{35,36}$. Los genes ermB, erm $C$ y erm $F$, son responsables de modificar la diana ribosomal gonocócica; su expresión varia por metilación de ARN $23 \mathrm{~S}^{37}$. Estos genes de metilasa están asociados con transposones conjugativos que facilitan la diseminación horizontal entre bacterias. Las mutaciones en la peptidiltransferasa del bucle del dominio $\mathrm{V}$ del ARNr $23 \mathrm{~S}$ también confieren la resistencia gonocócica a macrólidos ${ }^{38,39}$.

\section{Vacunas}

Las vacunas representan un hito fundamental en la prevención de las enfermedades infectocontagiosas, con repercusión excepcional en la salud mundial. Su valor es incuestionable.

Si bien las vacunas se usan de manera rutinaria para prevenir las enfermedades por Neisseria meningitidis, no hay vacuna alguna disponible para $N$. gonorrhoeae. Esto se debe a impedimentos tales como: la restricción de afectar a un solo hospedador natural (humanos), la ausencia de correlato serológico de inmunidad definible que surja de un episodio de gonorrea y la extraordinaria capacidad para variar la composición de sus antígenos de superficie, tanto entre cepas como dentro de la misma cepa, a lo largo del tiempo. En especial, este último factor ha complicado los esfuerzos para estudiar la patogénesis gonocócica y las respuestas inmunitarias del hospedero. Sin embargo, el objetivo de crear una vacuna específica para esta infección está en proceso, reconociéndose cuatro antígenos de superficie diferentes (porina, proteínas OPA, pilu y estructura de los glicanos), considerados como dianas de vacunas, identificando la contribución a la infección, la evasión inmunitaria, y por qué deben considerarse en el desarrollo de vacunas ${ }^{40}$. Estas investigaciones darán pie para la creación de vacunas inactivadas relacionadas a las proteínas de superficie.

La revista estadounidense Clinical Infectious Diseases, publicó un trabajo de investigación asegurando que la vacuna contra $N$. meningitidis grupo B en base a vesícula de la membrana externa (MeNZB OMV), empleada en Nueva Zelandia para el control de un brote de enfermedad meningocócica, es capaz de provocar también anticuerpos contra $N$. gonorrhoeae. Esto nace de la observación experimental al inmunizar conejos con el componente OMV o con los otros tres antígenos recombinantes que componen la vacuna Bexsero ${ }^{\mathrm{TM}}$ (adhesina A de Neisseria meningitidis (NadA), proteína recombinante de unión al factor $\mathrm{H}$ [fHbp] -proteína recombinante de fusión NHBA). 


\begin{tabular}{|c|c|c|c|c|}
\hline Región & Servicio de Salud & & & $\%$ \\
\hline Arica y Parinacota & $\begin{array}{l}\text { Arica } \\
\text { Privado }\end{array}$ & $\begin{array}{r}519 \\
13\end{array}$ & 532 & 4,2 \\
\hline Tarapacá & $\begin{array}{l}\text { Iquique } \\
\text { Privado }\end{array}$ & $\begin{array}{r}363 \\
75\end{array}$ & 438 & 3,5 \\
\hline Antofagasta & $\begin{array}{l}\text { Antofagasta } \\
\text { Privado } \\
\text { Otros }\end{array}$ & $\begin{array}{r}357 \\
178 \\
89\end{array}$ & 624 & 5,0 \\
\hline Atacama & $\begin{array}{l}\text { Atacama } \\
\text { Privado }\end{array}$ & $\begin{array}{l}48 \\
27\end{array}$ & 75 & 0,6 \\
\hline Coquimbo & $\begin{array}{l}\text { Coquimbo } \\
\text { Privado } \\
\text { Otros }\end{array}$ & $\begin{array}{r}677 \\
96 \\
1\end{array}$ & 774 & 6,2 \\
\hline Valparaíso & $\begin{array}{l}\text { Aconcagua } \\
\text { San Antonio } \\
\text { Viña del Mar } \\
\text { Privado } \\
\text { Otros }\end{array}$ & $\begin{array}{r}20 \\
230 \\
71 \\
231 \\
27\end{array}$ & 579 & 4,6 \\
\hline Metropolitana & $\begin{array}{l}\text { M. Central } \\
\text { M. Norte } \\
\text { M. Occidente } \\
\text { M. Oriente } \\
\text { M. Sur } \\
\text { M. Sur oriente } \\
\text { Privado } \\
\text { Otros }\end{array}$ & $\begin{array}{r}167 \\
72 \\
53 \\
133 \\
487 \\
483 \\
5.769 \\
139\end{array}$ & 7.303 & 58,7 \\
\hline O’Higgins & $\begin{array}{l}\text { Libertador B. O. } \\
\text { Privado }\end{array}$ & $\begin{array}{l}23 \\
59\end{array}$ & 82 & 0,7 \\
\hline Maule & $\begin{array}{l}\text { Maule } \\
\text { Privado }\end{array}$ & $\begin{array}{r}142 \\
7\end{array}$ & 149 & 1,2 \\
\hline Bío Bío & $\begin{array}{l}\text { Arauco } \\
\text { Bío Bío } \\
\text { Concepción } \\
\text { Ñuble } \\
\text { Talcahuano } \\
\text { Privado } \\
\text { Otros }\end{array}$ & $\begin{array}{r}16 \\
23 \\
383 \\
105 \\
214 \\
158 \\
1\end{array}$ & 900 & 7,2 \\
\hline Araucanía & $\begin{array}{l}\text { A. Norte } \\
\text { A. Sur } \\
\text { Privado }\end{array}$ & $\begin{array}{r}3 \\
111 \\
62\end{array}$ & 176 & 1,4 \\
\hline Los Ríos & $\begin{array}{l}\text { Valdivia } \\
\text { Privado }\end{array}$ & $\begin{array}{l}67 \\
33\end{array}$ & 100 & 0,8 \\
\hline Los Lagos & $\begin{array}{l}\text { Chiloé } \\
\text { Osorno } \\
\text { Reloncaví } \\
\text { Privado }\end{array}$ & $\begin{array}{r}75 \\
122 \\
392 \\
62\end{array}$ & 651 & 5,2 \\
\hline $\begin{array}{l}\text { Aisén } \\
\text { Magallanes }\end{array}$ & $\begin{array}{l}\text { Aisén } \\
\text { Magallanes } \\
\text { Privado }\end{array}$ & $\begin{array}{r}50 \\
7 \\
2\end{array}$ & $\begin{array}{r}50 \\
9\end{array}$ & $\begin{array}{l}0,4 \\
0,1\end{array}$ \\
\hline Sin información & & 15 & 15 & 0,1 \\
\hline Total & & & & 100 \\
\hline
\end{tabular}

Análisis bioinformático-posteriores evaluaron la similitud de los antígenos de MeNZB OMV y Bexsero ${ }^{\mathrm{TM}}$ con las proteínas gonocócicas. Los anticuerpos anti-gonocócicos inducidos por proteínas OMV similares a MeNZB, podrían explicar la disminución de gonorrea observada con anterioridad, después de la vacunación con MeNZB OMV en Nueva Zelandia. El alto nivel de anticuerpos NHBA anti-gonocócicos humanos generados por la vacunación con Bexsero ${ }^{\mathrm{TM}}$ puede proporcionar, también, una protección cruzada adicional contra la gonorrea ${ }^{11}$.

\section{Vigilancia de Neisseria gonorrhoeae en Chile}

El Laboratorio de Agentes de Infecciones de Transmisión Sexual de la Sección Bacteriología del ISP, laboratorio nacional de referencia de bacterias de importancia clínica, realiza vigilancias epidemiológicas de acuerdo con lo indicado en el Decreto Supremo N ${ }^{0}$ 7/ 2019 artículo 5': "Notificación de enfermedades transmisibles de declaración obligatoria", donde se detalla la lista de microorganismos que están sujetos a vigilancia y expone que la vigilancia deberá ser realizada en todos los establecimientos hospitalarios, públicos y privados, que efectúen aislamiento microbiano por sus propios medios o con el apoyo del ISP, de acuerdo a como lo dispone la norma técnica correspondiente.

Desde el 2010 hasta el 2018, este laboratorio tuvo la misión de llevar a cabo el Programa de Vigilancia de $N$. gonorrhoeae a nivel nacional, con el objetivo de caracterizar la infección en las regiones y registrar la resistencia a los antimicrobianos. A su vez, el ISP forma parte de la Red Internacional GASP-LAC (Gonococcal Antimicrobial Surveillance Programme in Latin America and the Caribbean), cuyo objetivo es reforzar las redes de Salud Pública que investigan la emergencia de resistencia antimicrobiana en aislados de $N$. gonorrhoeae en América Latina y el Caribe, a través de la estandarización y control de calidad externo.

El Boletín de Vigilancia publicado por el ISP en diciembre de $2019^{41}$, confirmó 12.457 cepas de $N$. gonorrhoeae, registrando un aumento del número de cepas confirmadas, con especial incremento los dos últimos años del período evaluado.

El 89,7\% de las cepas confirmadas durante el período provenían de pacientes de sexo masculino y $30,4 \%$ del grupo etario entre 20 y 24 años.

Más de la mitad de las cepas confirmadas (7.303 casos) procedían de la Región Metropolitana (58,6\%), seguida de la Región del Biobío con 900 cepas confirmadas (7,22\%), después la Región de Coquimbo con 774 y la Región de Los Lagos con 651 cepas confirmadas, equivalentes a 6,2 y $5,2 \%$, respectivamente. Todas las demás regiones no superaron las 624 cepas confirmadas por el ISP y son inferiores a 5\% (Tabla 3). 
En cuanto a la susceptibilidad antimicrobiana de las cepas confirmadas de $N$. gonorrhoeae, ceftriaxona y cefixima presentaron $100 \%$ de actividad in vitro durante el período evaluado; sin embargo, azitromicina y tetraciclina mostraron una disminución en su acción. Penicilina presentó un aumento de la resistencia antimicrobiana desde 33 a $71 \%$ con una mayor frecuencia de CIM categorizada en $64 \mu \mathrm{g} / \mathrm{mL}$ en los ocho años de análisis, al igual que ciprofloxacina, para la cual se registró un aumento de la resistencia desde 31 a $56 \%$ con valores en su mayoría de CIM de $2 \mu \mathrm{g} / \mathrm{mL}$ durante el mismo período.

\section{Conclusión}

Las infecciones gonocócicas han persistido históricamente asociadas a una alta morbilidad y mortalidad en todo el mundo. Si no son tratadas correctamente, y a tiempo, pueden afectar la reproducción humana. La aplicación de un solo antimicrobiano es poco recomendable para el tratamiento de la gonorrea, dada la alta prevalencia de cepas multirresistentes, por lo que se recomienda una combinación de fármacos, usualmente ceftriaxona $\mathrm{y}$ azitromicina.

Estos son motivos suficientes para desarrollar vacunas que nos protejan contra esta bacteria y, de paso, ayudarían e impulsarían el ahorro de antimicrobianos, lo que a su vez prolongaría la vida útil de los antimicrobianos autorizados, reducirían la inversión financiera y evitarían la evolución de otras enfermedades infecciosas o infertilidad, entre otras ventajas.

Dicho todo lo anterior es muy importante llevar a cabo un diagnóstico acertado para evitar la diseminación de este patógeno, especialmente en los casos asintomáticos, evaluar la sensibilidad in vitro de las cepas aisladas, prescribir un buen tratamiento e implementar campañas de salud en la población. Esto, a la espera de comprender el mecanismo molecular, interacciones metabólicas e inmunológicas que determinan los resultados de la infección $\mathrm{y}$ facilitar el diseño de una vacuna efectiva.

\section{Referencias bibliográficas}

1.- Hsu K K, Rice P A, Lieberman J M. Neisseria gonorrhoeae. In: Principles and Practice of Pediatric Infectious Diseases. Sara S. Long, ed. [Internet]. Elsevier; 2012. p. 741-8.e3. Disponible en: https://linkinghub.elsevier.com/ retrieve/pii/B9781437727029001288.

2.- Pardi G, Pérez M F, Pacheco A, Mata de Henning M. Algunas consideraciones sobre Neisseria gonorrhoeae. Acta Odontol Venez [Internet]. 2004;42:122-7. Disponible en: http://ve.scielo.org/scielo.php?script=sci arttext\&pid=S0001-63652004000200011\&lng= es\&nrm $=$ iso.

3.- Murray P R, Rosenthal ken S, Pfaüer M A. Manual of Clinical Microbiology [Internet]. $5^{\circ}$ Edición. Jorgensen JH, Carroll KC, Funke G, Pfaller MA, Landry ML, Richter SS, et al., editors. GEA Consultoría editorial, S.L.L. Washington, DC, USA: ASM Press; 2015. 311-21 p. Disponible en: http://doi.wiley. com/10.1128/9781555817381.

4.- Thompson M L. Tratamiento de la gonorrea en adolescentes y adultos. Rev Chilena Infectol 2000; 17(2): 158-60. http://dx.doi.org/10.4067/ S0716-10182000000200012.

5.- Hlatshwayo M, Reno H E L, Yarbrough M L. STI update: Testing, treatment, and emerging threats. Cleve Clin J Med [Internet]. 2019; 86(11): 733-40. doi: 10.3949/ccjm.86a.18098.

6.- Frieden T R, Jaffe H W, Cono J, Richards C L, Lademarco M F. Treatment guidelines. The Pharmaceutical Journal [Internet]. 2014; 64(3): 62. Disponible en: http://www.pharmaceutical-journal.com/ news-and-analysis/notice-board/treatmentguidelines/20065623.article.

7.- Koneman E, Giovanniello O, Klajn D, Preciado M. Diagnostico Microbiológico. Madrid, España 197 págs. 2008; 1385-403.

8.- García-Mendiola R, Aguilera-Arreola M G, Contreras-Rodríguez A. Neisseria gonorrhoeae. Rev Chilena Infectol. 2017; 34(3): 263-4. http://dx.doi.org/10.4067/S071610182017000300010

9.- Cruz S, Marina O. Caracterización fenotípica y genotípica de aislamientos colombianos de Neisseria gonorrhoeae, recuperados a través del programa nacional de vigilancia por laboratorio, 2013-2014. Biology 2019. Disponible en:http://bdigital.unal.edu.co/54432/

10.- Williams A M, Weston E J, Gift T L, Torrone E. Increases in the estimated number of reported gonorrhea cases among men who have sex with men: the role of testing. Sex Trans Dis. 2019; 46(11): 713-5. doi: 10.1097/ OLQ.0000000000001019.

11.- Semchenko E A, Tan A, Borrow R, Seib K L. The serogroup B Meningococcal vaccine Bexsero elicits antibodies to Neisseria gonorrhoeae. Jorgensen JH, Carroll KC, Funke G, Pfaller MA, Landry ML, Richter SS, et al., Clin Infect Dis 2019; 69(7): 1101-11. https:// doi.org/10.1093/cid/ciy1061.

12.- Queirós C, da Costa J B. Oral transmission of sexually transmissable infections: a narrative review. Acta Médica Portuguesa [Internet]. 2019; 32(12): 776. https://doi.org/10.20344/ amp.12191.

13.- Tejeros García R, Muñoz Molineros J, Lacasa Díaz M J, Solís Cuesta F, Rivero A, Rodríguez
López F de C, et al. Genococcal arthritis in an HIV positive patient]. An Med Interna 2003; 20(7): 389-91. PMID: 12951980.

14.- CDC. La conjuntivitis en los recién nacidos. Centros para el Control y la Prevencion de Enfermedades. 2017. Disponible en: https://www.cdc.gov/ conjunctivitis/newborns-sp.html

15.- Zúñiga M M. Neisseria gonorrhoeae: Un patógeno que impone grandes retos. Revista Colombiana de Enfermería. 2016; 5(5): $67-70 \mathrm{https} / / /$ doi.org/10.18270/rce. v5i5.1425.

16.- Kenneth J R, Ray G. Sherris Microbioloía Médica. [Internet]. $5^{\circ}$ Edición. Hill MG, editor. Mexico; 2011. 415 p. Disponible en: http:// ifssa.ddns.net/biblioteca/files/original/8330679 743987ea4d48b74419346d18a.pdf.

17.- Sosa Puente J. Estudio de la resistencia a los antimicrobianos y caracterización molecular en cepas de Neisseria gonorrhoeae aisladas en Cuba. Thesis 2002 (julio):130. doi: 10.13140/ RG.2.1.4714.0326.

18.- Ajello G, Bopp C, Elliott J, Facklam R, Knapp J S, Popovic T, et al. Manual de Laboratorio para la identificación y pruebas de susceptibilidad a los antimicrobianos de patógenos bacterianos de importancia para la Salud Pública en el mundo en desarrollo. Haemophilus influenzae, Neisseria meningitidis, Streptococcus pneumoniae. Organización Mundial de la Salud, Enfermedades Transmisibles: Vigilancia y Respuesta [Internet]. 2004;4967. Disponible en: https://apps.who.int/iris/ handle/10665/68554. 
19.- Otero-Guerra L, Fernández-Blázquez A, Vazquez Valdés F. Diagnóstico rápido de las infecciones de transmisión sexual. ELSEVIER. 2017; 35(7): 444-50. Disponible en: http:// dx.doi.org/10.1016/j.eimc.2017.01.004.

20.- Hogan J, Kop J A, McDonough S. Nucleic acid probes and methods for detecting Neisseria gonorrhoeae [Internet]. Vol. 1. San Diego, CA (US); US 7,172,863 B1, 2007. Disponible en: https://patents.google.com/patent/ CA2031490A1/en.

21.- Wilder C N. White Paper: The rise of multidrug-resistant strains and need for new therapeutic approaches. ATCC Credible leads to incredible [Internet]. 2019;8-11. Disponible en: https://www.who.int/news/item/27-02-2017who-publishes-list-of-bacteria-for-which-newantibiotics-are-urgently-needed.

22.- Teglia O. Neisseria gonorrhoeae en la era de la multiresistencia. Rev Med Rosario 2016; 82: 17-30. Disponible en: http://www. circulomedicorosario.org/Upload/Directos/ Revista/76356fTeglia Neisseria gonorrheae y multirresistencia.pdf.

23.- Unemo M, Shafer W M. Antimicrobial resistance in Neisseria gonorrhoeae in the 21st Century: past, evolution, and future. Clin Microbiol Rev. 2014; 27(3): 587-613. https:// doi.org/10.1128/CMR.00010-14.

24.- Lewis D A. The gonococcus fights back: is this time a knock out? Sex Trans Infect. 2010 Nov 1; 86(6): 415-21. doi: 10.1136/sti.2010.042648.

25.- Palace S G, Wang Y, Rubin D H F, Welsh M A, Mortimer T D, Cole K, et al. RNA polymerase mutations cause cephalosporin resistance in clinical Neisseria gonorrhoeae isolates. eLife 2020 Feb 3; 9: 1-22. https://dx.doi. org $/ 10.7554 \% 2 \mathrm{FeLife} .51407$.

26.- Galimand M, Gerbaud G, Courvalin P. Spectinomycin resistance in Neisseria spp. due to mutations in $16 \mathrm{~S}$ rRNA. Antimicrob Agents Chemother. 2000;44(5):1365-6. https://doi. org/10.1128/AAC.44.5.1365-1366.2000.

27.- Vakulenko SB, Mobashery S. Versatility of aminoglycosides and prospects for their future. Clin Microbiol Rev 2003; 16(3): 430-50. https://dx.doi.org/10.1128\%2FC MR.16.3.430-450.2003.
28.- Dillon J-A, Parti R, Thakur S. Antibiotic resistance in Neisseria gonorrhoeae: will infections be untreatable in the future? ResearchGate. 2015; 35(January):5. Disponible en: https://www.researchgate.net/ publication/272155974_Antibiotic_Resistance_ in_Neisseria_gonorrhoeae_Will_Infections_be Untreatable in the Future.

29.- Hu M, Nandi S, Davies C, Nicholas R A. High-level chromosomally mediated tetracycline resistance in Neisseria gonorrhoeae results from a point mutation in the rpsj gene encoding ribosomal protein S10 in combination with the $m t r R$ and $p e n B$ resistance determinants. Antimicrob Agents Chemother 2005 Oct;49(10):4327-34. https://doi.org/10.1128/ AAC.49.10.4327-4334.2005.

30.- Starnino S, Neri A, Stefanelli P, Neisseria gonorrhoeae Italian study group. Molecular analysis of tetracycline-resistant gonococci: rapid detection of resistant genotypes using a real-time PCR assay. FEMS Microbiology Letters 2008;286(1):16-23. https://doi. org/10.1111/j.1574-6968.2008.01244.x

31.- Belland R J, Morrison S G, Ison C, Huang W M. Neisseria gonorrhoeae acquires mutations in analogous regions of gyrA and $\operatorname{parC}$ in fluoroquinolone-resistant isolates. Molecular Microbiol [Internet]. 1994;14(2):371-80. https://doi.org/10.1111/j.1365-2958.1994. tb01297.x.

32.- Mavroidi A, Tzouvelekis L S, Tassios P T, Flemetakis A, Daniilidou M, Tzelepi E. Characterization of Neisseria gonorrhoeae strains with decreased susceptibility to fluoroquinolones isolated in Greece from 1996 to 1999. J Clin Microbiol 2000 Sep; 38(9): 3489-91. https://doi.org/10.1128/ JCM.38.9.3489-3491.2000.

33.- Shultz T R, Tapsall J W, White P A. Correlation of in vitro susceptibilities to newer quinolones of naturally occurring quinolone-resistant Neisseria gonorrhoeae strains with changes in gyrA and parC. Antimicrob Agents Chemother 2001; 45(3): 734-8. https://doi.org/10.1128/ AAC.45.3.734-738.2001

34.- Roberts MC. Update on macrolide-lincosamide- streptogramin, ketolide, and oxazolidinone resistance genes. FEMS Microbiol Letters 2008; 282(2): 147-59. doi: $10.1111 /$ j.15746968.2008.01145.x.

35.- Luna V A, Cousin S, Whittington W L H, Roberts M C. Identification of the conjugative $m e f$ gene in clinical Acinetobacter junii and Neisseria gonorrhoeae isolates. Antimicrob Agents Chemother 2000; 44(9): 2503-6. doi: 10.1128/AAC.44.9.2503-2506.2000.

36.- Cousin S, Whittington W L H, Roberts M C. Acquired macrolide resistance genes in pathogenic Neisseria spp. isolated between 1940 and 1987. Antimicrob Agents Chemother 2003; 47(12): 3877-80. https://dx.doi.org/10.11 28\%2FAAC.47.12.3877-3880.2003.

37.- Ng L-K, Martin I, Liu G, Bryden L. Mutation in 23S rRNA associated with macrolide resistance in Neisseria gonorrhoeae. Antimicrob Agents Chemother 2002;46(9):3020-5. https://doi. org/10.1128/AAC.46.9.3020-3025.2002.

38.- Roberts M C, Chung W O, Roe D, Xia M, Marquez C, Borthagaray G, et al. Erythromycin-resistant Neisseria gonorrhoeae and oral commensal Neisseria spp. carry known rRNA methylase genes. Antimicrob Agents Chemother 1999; 43(6): 1367-72. PMID: 10348754.

39.- Alm R A, Lahiri S D, Kutschke A, Otterson L G, McLaughlin R E, Whiteaker J D, et al. Characterization of the novel DNA gyrase inhibitor AZD0914: low resistance potential and lack of cross-resistance in Neisseria gonorrhoeae. Antimicrob Agents Chemother 2015; 59(3): 1478-86. https://doi.org/10.1128/ AAC.04456-14.

40.- Russell M W, Jerse A E, Gray-Owen S D. Progress toward a gonococcal vaccine: the way forward. Front Immunol 2019 Oct 15; 10(October): 1-18. https://doi.org/10.3389/ fimmu.2019.02417.

41.- Instituto de Salud Publica (ISP). Ministerio de Salud de Chile. Vigilancia de Neisseria gonorrhoeae Chile, 2010-2018. Boletín de Vigilancia de Laboratorio 2019; 9(12): 1-13. Disponible en: https://www.ispch.cl/sites/ default/files/BoletínGonorrea-27402020B FINAL_web.pdf. 